\title{
ENSEÑANZA DE LA LENGUA Y LA LITERATURA
}

\section{(Propuestas metodológicas y bibliográficas)}

\author{
José Romera Castillo
}

(Madrid: UNED, 1996, 332 págs.)

A los dieciocho años de la primera edición de su Didáctica de la Lengua y la Literatura. Método y práctica (Madrid: Playor, 1979), José Romera Castillo vuelve a dedicar un volumen completo a tan importante tema. En este período de tiempo, no sólo ha corregido y aumentado ese texto, sino que además ha publicado diversos artículos, pronunciado conferencias, e impartido cursos (entre otros, uno perteneciente al «Programa de formación del Profesorado» de la UNED), sobre la materia. Algunos de esos trabajos aparecen ahora reunidos en esta Enseñanza de la Lengua y la Literatura, junto con propuestas metodológicas que no habían visto la luz, lo que ha hecho mucho más accesible a profesores e investigadores un conjunto de textos que se encontraban dispersos en el nutrido panorama de congresos y revistas de preocupación por la enseñanza de la Lengua y la Literatura. Se organiza el texto en tres apartados: «Enseñanza de la Lengua», «Enseñanza integrada de la Lengua y la Literatura» y «Enseñanza de a Literatura», sin perder de vista los aspectos semióticos. 
El primero de estos bloques abarca cuatro cuestiones que resultan fundamentales en la enseñanza de la Lengua como son las del léxico, la sintaxis y la expresión escrita. En todos los casos realiza una breve panorámica de la cuestión y sugiere diversidad de ejercicios que pueden resultar de utilidad al profesor no sólo para facilitar el aprendizaje en sí, sino para investigar el progreso del mismo dentro del aula. Pero sumadas a éstas, aparece tratada una cuestión más, la del discurso como área de trabajo en Didáctica de la Lengua, cosa que no siempre ha sido considerada en los manuales al uso, y que sólo recientemente se ha venido extendiendo como referente en el panorama de los trabajos sobre enseñanza de la comunicación oral y escrita. Un apéndice bibliográfico aborda, además de las cuestiones tratadas, los campos de la Didáctica de la Lengua, la lectoescritura, ortografía y expresión oral.

Un bloque más breve que el anterior se dedica a una cuestión tan concreta como espinosa: la integración o no, y en qué condiciones, de la enseñanza de la Lengua y la Literatura. En un punto en el que tan frívolamente se ha argumentado y legislado y en el que tanto se ha dado por supuesto, el autor mantiene una actitud que, por lógica y coherente, no ha sido la más común en el panorama de textos sobre la cuestión: partir de la fundamentación teórica. Una fundamentación teórica que no significa atiborrar a los jóvenes con reflexiones de gran abstracción, como suele argumentarse para eludirla, sino que se dirige a un ser tan adulto y tan formado que tiene como responsabilidad organizar con las mayores garantías el proceso de aprendizaje de los más jóvenes de su sociedad: el profesor.

Para ello realiza una concisa panorámica de las posturas fundamentales sobre la pertenencia o no del mensaje literario a la esfera de lo lingüístico, a partir de la que presenta él su opción personal: el linguístico y el literario son dos sistema diferentes, y la enseñanza de uno de ellos no puede realizarse exclusivamente a través del otro. Cosa diferente es la utilidad, en determinados momentos del proceso educativo, de un trabajo de aprovechamiento de los textos literarios para un aprendizaje lingüístico, lo cual parece positivo al autor. Pero para ello hace falta contar con textos literarios adecuados a las distintas edades y propósitos, y por ello nos ofrece el libro diversos recursos, desde las más diversas Historias de la Literatura infantil hasta colecciones de clásicos anotadas para jóvenes, pasando por un variado elenco de guías de lectura, sin olvidar boletines de información sobre novedades en literatura infantil y juvenil y sus índices informatizados. Finaliza este bloque con un apéndice de una cincuentena de títulos dedicados a Didáctica de la Lengua y la Literatura. 
«Enseñanza de la Literatura» es la tercera de las secciones en que se divide el libro. Frente a la costumbre, de algunos (y conocidos) textos, de tratar esta parte como un mero apéndice donde servilmente se confirma absolutamente todo lo dicho a propósito de la lengua, o donde de la fundamentación científica de la parte linguiística se pasa a una breve enumeración de algunas actividades sueltas presididas por un vulgar espontaneísmo, pueden encontrarse en el libro amplios apartados dedicados a cuestiones fundamentales del ámbito de la docencia de lo literario. Y todo ello con el acompañamiento de una bibliografía cuyo calibre contrasta agudamente con el de numerosas publicaciones sobre Didácticas de la Literatura, algunas de las cuales, por imperativo legal, resultan de lectura casi obligatoria (y de aplicación más o menos forzosa) para los profesores.

Así, el problema de la enseñanza de las literaturas hispánicas no castellanas o la posición de la Literatura en el seno del conjunto de las enseñanzas, junto con un repaso de algunas tendencias actuales, forman el capítulo inicial. Tres géneros de especial impacto en la enseñanza, como son el cuento, la poesía y el teatro son tratados en sendos capítulos, tanto en una exposición de las líneas fundamentales del estado de la cuestión como en una panorámica guiada de recursos metodológicos y bibliográficos. A continuación, dos capítulos afrontan cuestiones poco tratadas más allá del artículo ocasional o el reportaje más o menos de divulgación: el uso de los multimedia, aplicado específicamente a la enseñanza de la Literatura, y la enseñanza de lo autobiográfico en los niveles iniciales y medios. Ocupan el capítulo final seis generosos apéndices bibliográficos, dedicados a «Didáctica de la Literatura», «Literatura Infantil y Juvenil», «Lectura y Técnicas de Animación», «Comentario de Textos», «El Cómic» $\mathrm{y}$ «Medios de Comunicación Social».

Ocupa la orientación bibliográfica un lugar importante dentro del libro, como ha podido irse viendo. Esta orientación, aparte de la rigurosa enumeración de las obras mencionadas en cada apartado, incluye pistas concretas y guías para que el menos experto en alguno de los campos pueda introducirse en los temas que se van abordando. Además, muy amplios listados, con la inclusión de títulos recientes, serán de indudable utilidad para quienes quieran profundizar en un tema concreto, y muy especialmente para aquellos investigadores en Didáctica de la Lengua o de la Literatura que, sin despreciar el papel de lo intuitivo en la investigación, o el papel de la creatividad de los niños y jóvenes en el trabajo del aula, optan por no olvidar una correcta fundamentación teórica en su trabajo. Todos ellos sabrán encontrar buen provecho.

Jesús Manuel Corriente Cordero 